\title{
Michela Gardini, Joséphin Péladan. Esthétique, magie et politique
}

\section{Maria Emanuela Raffi}

\section{Q OpenEdition}

1 Journals

\section{Edizione digitale}

URL: http://journals.openedition.org/studifrancesi/4446

DOI: $10.4000 /$ studifrancesi.4446

ISSN: 2421-5856

\section{Editore}

Rosenberg \& Sellier

\section{Edizione cartacea}

Data di pubblicazione: 1 settembre 2016

Paginazione: 358

ISSN: 0039-2944

\section{Notizia bibliografica digitale}

Maria Emanuela Raffi, « Michela Gardini, Joséphin Péladan. Esthétique, magie et politique », Studi

Francesi [Online], 179 (LX | II) | 2016, online dal 01 septembre 2016, consultato il 18 septembre 2020.

URL : http://journals.openedition.org/studifrancesi/4446; DOI : https://doi.org/10.4000/studifrancesi. 4446

Questo documento è stato generato automaticamente il 18 settembre 2020.

\section{(c) 9 (i) $\Theta$}

Studi Francesi è distribuita con Licenza Creative Commons Attribuzione - Non commerciale - Non opere derivate 4.0 Internazionale. 


\title{
Michela Gardini, Joséphin Péladan. Esthétique, magie et politique
}

\author{
Maria Emanuela Raffi
}

\section{NOTIZIA}

MICHELA GARDINI, Joséphin Péladan. Esthétique, magie et politique, Paris, Classiques Garnier, 2015, 208 pp.

1 Al singolare personaggio di Péladan, nelle sue diverse personificazioni, è dedicato il saggio di Michela Gardini, impreziosto da una suggestiva iconografia. L'incrociarsi della ricca aneddotica relativa all'autore con l'oggettività della sua produzione letteraria appare l'elemento conduttore dello studio, che analizza l'«opération performative et spectacularisante d'autopromotion» attuata da Péladan nella sua triplice veste di Sâr Mérodack, di Mago e di fondatore dell'Ordre de la Rose+Croix. La fotografia gioca in questa presentazione rituale di sé un ruolo fondamentale, che Péladan condivide con molti scrittori di fine Ottocento, ma che presenta, nella serie di clichés che lo riguardano, evidenti elementi dinamici, quasi cinematografici, «comme une séquence qui soustrairait la figuration à la fixité typique de la photographie». Anche il suo ruolo di autore appare come eminentemente dinamico e soggetto a continue metamorfosi; romanziere, critico d'arte, storico, autore di teatro, archeologo e filosofo per sua stessa dichiarazione, Péladan allarga e radicalizza «la recherche de l'absolu par la mise en jeu de son propre corps», puntando con ciò alla realizzazione «de la perfection intellectuelle et spirituelle». Eppure, in controtendenza apparente rispetto a tanta esibizione di sé, nei ventuno romanzi della Décadence Latine la scelta dell'autore sembra quella del distacco dalla vita contemporanea per «une vie retirée et isolée», all'interno della quale continuare il suo percorso di sublimazione. Le tappe di questo percorso a un tempo esibito e sapientemente occultato, ma sempre narcisistico e autoreferenziale, sono seguite con attento interesse dall'A., che fornisce all'opera e alle convinzioni di Péladan il continuo supporto di legami con altri autori e con altre espressioni letterarie, artistiche e filosofiche, tracciando un intenso panorama dell'esoterismo e delle nuove 
consapevolezze scientifico-spiritualiste che costituiscono il tessuto di una consistente parte della sensibilità culturale di fine Ottocento. Ne risulta un ritratto forse un po' troppo ricco di suggestioni e di accostamenti a volte epidermici - come quello fra Sâr Mérodack e Mafarka nel capitoletto «Péladan futuriste» -, ma certamente interessante, che si conclude, nell'«Annexe», con tre articoli pubblicati da Péladan nel 1904 sulla scoperta del radio da parte dei Curie, che lo scrittore considera nella sua ottica tesa a «fonder une doctrine unitaire qui puisse réconcilier les données scientifiques avec les instances métaphysiques». 